\title{
Effects of Strontium Ranelate on Alveolar Ridge Morphology Augmentation
}

\author{
Efectos del Ranelato de Estroncio en el Aumento del Reborde Alveolar
}

Jing Xuan'; Xiu-Ping Wu' ; Tae-Geon Kwon² ; Hee-Moon Kyung² \& Li Bing¹

XUAN, J.; WU, X. P.; KWON, T. G. ; KYUNG, H. M. \& BING, L. Effects of strontium ranelate on alveolar ridge morphology augmentation. Int. J. Morphol., 35(4):1328-1331, 2017.

SUMMARY: The objective of this study was to compare the Primary and Secondary stability of immediate implant placement with Alveolar Ridge Augmentation (ARA) and Strontium Ranelate (SR) as aids to enhance the stability using Resonance Frequency Analysis (RFA). Fifty eight subjects ideal for immediate implants were assigned to two groups to compare the primary and secondary stability of the implant using Alveolar Ridge Augmentation and oral strontium ranelate. They were tested for primary stability on placement of the implant and after eight weeks of placement for secondary stability. The stability was measured using resonance frequency analysis. Both the procedures showed an improvement in the stability but the Alveolar Ridge Augmentation procedure showed a significantly better primary stability $(\mathrm{P}<.03)$ and the secondary stability $(\mathrm{P}<.00)$. The means of the implant stability quotient value (ISQ) for the Alveolar ridge augmentation procedure was 74.2 for primary stability, and 83.34 for secondary stability. With the enhancement of stability with both the procedures Alveolar Ridge Augmentation proved to be a better procedure to achieve successful results of an immediately placed implant.

KEY WORDS: Morphology; Alveolar ridge augmentation; Strontium ranelate; Dental implants.

\section{INTRODUCTION}

Dental implants over the years have made a mark in the field of dentistry, as years past implants have provided both the surgeon as well as the patient a variety of methods in order to obtain a successful result. Keeping healing time in mind, placing an implant in a freshly extracted socket has gained popularity, with literature presenting clear guidelines for patient selection and methods of good outcomes (Zarandi \& Novin, 2017; Schiegnitz et al., 2017; Chuka et al., 2017). Stability plays an important role in Osseointegration and primary stability directly influences the osseointegration of implants (Chen et al., 2017; Kim et al., 2017; Dhaliwal et al., 2017). A pre requisite for direct bone formation on the implant surface is achieved by initial implant stability on placement. The primary stability of an implant is replaced by the secondary implant stability. As a result of the formation of new woven and lamellar bone during the healing process on to the implant surface.

As stability has been a fragile component in the success of an implant, methods to improve the stability has been given utmost importance. Among them ARA has shown prospering results. Small localized vertical/horizontal ridge defects has been treated with GBR (Guided Bone Regeneration) with the particulate augmentation material for implant site development (Le \& Burstein, 2008; Kaitsas et al., 2015; AlHezaimi et al., 2016). Autogenous bone (from the same individual) is widely viewed as the gold standard material because of its osteogenic, osteoinductive, osteoconductive capacities (Kolk et al., 2012). On the other hand pharmaceutical agents have showed promising results in enhancing osseointegration, one such agent is SR. The beneficial effects of SR being to prevent bone loss by maintaining bone formation at a high level and inhibiting bone resorption. In overiectomized rats, SR elevated bone formation whereas it prevented bone loss by reducing bone resorption. The exact mechanism by which SR exhibits these effects has not been definitely understood, but may include stimulation of osteoblast proliferation and inhibit osteoclast formation.SR is a promising new agent for the treatment of postmenopausal osteoporosis in women and a study also

\footnotetext{
${ }^{1}$ Stomatology Hospital, Shanxi Medical University, Taiyuan, China.

${ }^{2}$ School of Dentistry, Kyungpook National University, Daegu, Korea.

Shanxi Province International Science and Technology Cooperation Project, No.2015081030;

Shanxi Province returned overseas students research funding projects, No.2015-053.
} 
showed that SR was well tolerated and a dose of $2 \mathrm{~g}$ daily offered the best combination of efficacy and safety (Amman, 2004; Abrahamsen et al., 2013; Bayhan et al., 2013). The objective of this study was to compare the Primary and Secondary stability of immediate implant placement with Alveolar Ridge Augmentation (ARA) and Strontium Ranelate (SR) as aids to enhance the stability using Resonance Frequency Analysis (RFA).

\section{MATERIAL AND METHOD}

Experimental preparation. Fifty eight healthy subjects ideal for immediate implant placement at The Dental hospital, Shanxi Medical University were randomly assigned to two groups. All the treatment planning, surgical extractions and implant placement were performed by a single surgeon. Inclusion criteria for the study are summarized in Table I. In Group A, ARA procedure was associated with the placement of the Implant. Group B, Oral SR was prescribed after the Implant was placed in the fresh extraction site.

Clinical examination. In all cases, clinical examination included reviews of medical and dental histories, radiographic assessment, and evaluations of oral hygiene. Before treatment, the patient's ability to commit to longterm follow-up was assessed. Study casts were fabricated and mounted on a semi-adjustable articulator using a face bow transfer and vertical registration to determine jaw relationships, available occlusal dimension, proposed implant position, crown-implant ratio, and potential complications. Prosthetic wax-up and surgical template were fabricated to allow guided placement of the implants relative to the planned prosthesis. The treatment plan and alternative options were discussed, and a signed informed consent was obtained from each patient before treatment. Teeth were carefully removed to maintain the extraction walls as much as possible. Implants (Nobal Replace Tapered, Nobal Bio Care Inc. Zurich, Switzerland) were placed according to the manufacturer's protocol. Criteria for immediate placement of implants included initial implant stability and 4-walled self-contained immediate extraction sites.

Autogenous Symphseal bone grafting procedure and prescription of Oral Strontium Ranelate. Group A subjects received an ARA around the placed implant. The autogenous bone graft was taken from the symphysis region of the same subject. For the symphysis graft, "the Rule of 5's" was respected, which requires $5 \mathrm{~mm}$ of bone present beyond the propose osteotomy margins and the surrounding structures. Antibiotics were prescribed preoperatively because the bone is exposed to oral bacteria during the procedure and it also aides the healing process by clearing the oral bacteria. The recipient site is assessed before so as to measure the size, volume and shape of the bone. Osteotomy was performed using a piezotome instrument because it results in a precise cut.Group B were prescribed oral Strontium Ranelate 2gms/ day for a period of 8 weeks.

Measurement of Primary and Secondary Stability. RFA measurements were performed immediately following implant placement and 8 weeks post implant placement using (Osstell mentor, Integration Diagnostics AB, Goteborg, Sweden) according to the manufacturer's recommendations. The measuring devices (Smartpeg) were attached to the implant using $10 \mathrm{Ncm}$ of torque. All measurements were performed with the probe (Osstell mentor Probe II) aiming from the buccal directions. The probe was held at a distance of 2-3 mm until the instrument displayed the implant stability quotient value (ISQ).

Statistical analysis. First, data were subjected to descriptive statistical analysis (SPSS, Chicago, IL, USA). The difference in resonance frequency values between the two groups at the initial and 8 week post implant placement was tested for significance using t test with a level of significance of $0.05 \%$.

\section{RESULTS}

The ISQ values for the primary stability showed a highly significant statistical difference between the two groups with a significance value of .035. The implants of Group A which were supported with the alveolar ridge augmentation procedure showed a higher mean ISQ value of 74.20, and Group B which were prescribed with Strontium Ranelate showed a mean ISQ value of 70.41 (Table II).

The ISQ values for the secondary stability showed a highly significant statistical difference between the two groups with a significance value of .000 . The implants of Group A which were supported with the alveolar ridge augmentation procedure showed a higher mean ISQ value of 83.34, and Group B which were prescribed with Strontium Ranelate showed a mean ISQ value of 75.55 (Table III).

A highly statistically significant relationship was found between the resonance frequency analysis, the procedures and the time of measurement. The ISQ values were higher in the group which had alveolar ridge augmentation irrespective of the time of measurement. 
Table I. Criteria for Dental Implant Placement

\begin{tabular}{cl}
\hline SUBJECTS & CRITERIA \\
\hline Inclusion & At least 18 years of age \\
& Systemically and Dentally healthy \\
& Demonstrated ability to maintain oral hygiene \\
& Willingness and ability to commit to follow-up \\
& Provide signed informed consent \\
& Properly evaluation of the quantity and quality of \\
& bone \\
Exclusion & Lack of skele tal maturity \\
& Uncontrolled disease or conditions that could \\
& Impede bone healing or soft tissue heal th \\
& Mental, emotional, or lifestyle factors that \\
& could adversely impact treatment and follow- up
\end{tabular}

Table II. Primary Stability measurement (ISQ values) at placement of implants in the two groups

\begin{tabular}{ccc}
\hline Group & Mean \pm SD & P \\
\hline ARA & $74.20 \pm 6.9 *$ & .035 \\
SR & $70.41 \pm 5.9 *$ & \\
\hline$*:$ P $<.05$ & &
\end{tabular}

Table III. Secondary Stability measurement (ISQ values) at placement of implant in the two groups.

\begin{tabular}{lcc}
\hline Group & Mean \pm SD & P \\
\hline ARA & $83.34 \pm 5.6 * * *$ & .000 \\
SR & $75.55 \pm 5.8 * * *$ & \\
\hline$* * *: \mathrm{P}<0.001$ & &
\end{tabular}

\section{DISCUSSION}

As from the results of the present study, alveolar ridge augmentation and Strontium Renalate following immediate implant placement have shown to provide good primary and secondary stability (Benic et al., 2016). The study, showed a highly statistically significant difference in the primary and secondary stability values in Group A (Alveolar ridge augmentation), even though the procedure was technique sensitive and is similar to the results that single-stage implant placement and simultaneous grafting with mineralized particulate allograft showed promising outcome in correcting small and medium sized vertical labial wall defects.

While comparing the primary stability of implants placed in the two groups, Group A showed a mean ISQ value of 74.20 and Group B showed a value of 70.41 (Table II). Although the primary stability is obtained as a result of manual placement of the implant in the desired position which was a similar protocol performed to both the test groups. When compared between the two groups there was a significant difference $(\mathrm{P}=.03)$, which mean that the alveolar ridge augmentation procedure had supplemented the stability because the grafted bone was packed tightly around the implant. Immediate placement of implants into a fresh extraction socket with care taken that the implant has been placed in a stable and desired position in order to provide long term success. This fact may be the reason for the difference in mean values between the groups when measured for primary stability were statistically different. Never the less the quality and quantity of the bone play a role on the primary stability and since they patients selected for the study were evaluated for the same it played an important role. Similarly while the secondary stability of the implants placed in the two groups were compared the Group A showed a mean ISQ value of 83.34 and Group B showed a value of 74.20 (Table III), with a highly significant difference between the two groups $(\mathrm{P}=.00)$. An autogenous bone transplantation is considered to show an acceleration on the healing as it brings along the osteogenic genic cells and the osteogenic growth factors to the augmentation site.

A controlled clinical trial which stated, that treatment of post-menopausal women with established osteoporosis with SR $2 \mathrm{~g}$ daily for 2 years resulted in an increase in lumbar bone mineral density about $3 \%$, and an improvement in osseointegration was obtained by mechanical fixation and microarchitecture of the bone surrounding the implant, these results coordinated with the results of this study which shows probable increase in bone density and supporting the reason for the improvement of the stability of the implants when comparing the primary and secondary stability. SR in a previous study has shown to stimulatebone collagen synthesis in vitro, as a result of a modification of the bone matrix mainly constituting type I collagen. It has also consistently shown in rat calvaria to stimulate DNA synthesis and bone collagen synthesis.SR has demonstrated to stimulate bone formation, which may be beneficial for Osseo integration, and it has also been reported to stimulate preosteoblastic and osteoblastic cell replication and synthesis of collagenous matrix. On the other hand SR has shown an increase in the alkaline phosphatase activity which is a marker for an increase in collagen synthesis and osteoblast differentiation. This supports the result which shows an improvement of the primary stability to the secondary stability (Canalis et al., 1996; Barbara et al., 2004; Kim et al., 2015).

Alveolar ridge augmentation on the other hand requires 8 weeks for the completion of healing of the surgical site, during this time ideal amount of bone activities are expected to be completed. It was stated that the successful placement of implants in autologous grafts is more predictable when the implants are placed 6 to 9 months after the bone grafting procedure.14 The ARA procedure as 
considered to show an increase in bone activity which is an important factor for the remodelling process and for the formation of bone sufficient enough to osseointegrate to the implant surface, SR is known to reduce osteoclastic activity and induce osteoblastic activity, which eventually interrupts the natural process of bone remodelling. Although histological analysis can provide a better understanding of the outcomes of the two procedures in terms of microstructural osseointegration, the current study was able to provide a clear picture on the ISQ values using resonance frequency as a valuable tool in calculating the stability of dental implants. Although, the ISQ values showed that both the procedure alveolar ridge augmentation and the use of Strontium Renalate were able to provide acceptable stability, the group A with subjects who underwent an alveolar ridge augmentation procedure resulted in a statistically significant difference in terms of primary and secondary stability, proving to be the better procedure.

Alveolar ridge augmentation and oral intake of Strontium Renalate were both able to provide an improvement in the stability of dental implants placed in fresh implant sockets. But in comparison alveolar ridge augmentation proved to be a better procedure to improve stability.

XUAN, J.; WU, X. P.; KWON, T. G.; KYUNG, H. M. \& BING, L. Efectos del ranelato de estroncio en el aumento del reborde alveolar. Int. J. Morphol., 35(4):1328-1331, 2017.

RESUMEN: El objetivo de este estudio fue comparar la estabilidad primaria y secundaria de la colocación inmediata del implante con el aumento de reborde alveolar (ARA) y el ranelato de estroncio (SR) como ayudas para mejorar la estabilidad mediante el análisis de frecuencia de resonancia (RFA). Cincuenta y ocho sujetos, ideales para implantes inmediatos, fueron asignados a dos grupos para comparar las estabilidades primaria y secundaria del implante usando el aumento del reborde alveolar y el ranelato de estroncio oral. Se efectuaron pruebas de estabilidad primaria en la colocación del implante, y después de ocho semanas para la estabilidad secundaria. La estabilidad se midió utilizando análisis de frecuencia de resonancia. Ambos procedimientos mostraron una mejora en la estabilidad, sin embargo el procedimiento del aumento del reborde alveolar mostró una estabilidad primaria significativamente mejor $(\mathrm{P}<0,03)$ que la estabilidad secundaria $(\mathrm{P}<0,00)$. Las medias del valor de cociente de estabilidad del implante (ISQ) para el procedimiento de aumento de reborde alveolar fueron 74,2 para la estabilidad primaria y 83,34 para la estabilidad secundaria. Se observó una mejora de la estabilidad en ambos procedimientos, el aumento del reborde alveolar demostró ser un mejor procedimiento para lograr resultados exitosos del posicionamiento de implante inmediato.

PALABRAS CLAVE: Morfología; Aumento del reborde alveolar; Ranelato de estroncio; Implantes dentales.

\section{REFERENCES}

Abrahamsen, B.; Grove, E. L. \& Vestergaard, P. Nationwide registry-based analysis of cardiovascular risk factors and adverse outcomes in patients treated with strontium ranelate. Osteoporos. Int., 25(2):757-62, 2013.

Al-Hezaimi, K.; Ramalingam, S.; Al-Askar, M.; ArRejaie, A. S.; Nooh, N.; Jawad, F.; Aldahmash, A.; Atteya, M. \& Wang, C. Y. Real-time-guided bone regeneration around standardized critical size calvarial defects using bone marrow-derived mesenchymal stem cells and collagen membrane with and without using tricalcium phosphate: an in vivo micro-computed tomographic and histologic experiment in rats. Int. J. Oral Sci., 8(1):7-15, 2016.

Amman, P.; Shen, V.; Robin, B.; Mauras, Y.; Bonjour, J. P. \& Rizzoli, R. Strontium ranelate improves bone resistance by increasing bone mass and improving architecture in intact female rats. J. Bone Miner. Res., 19(12):2012-20, 2004.

Barbara, A.; Delannoy, P.; Denis, B. G. \& Marie, P. J. Normal matrix mineralization induced by strontium ranelate in MC3T3-E1 osteogenic cells. Metabolism, 53(4):532-7, 2004.

Bayhan, I.; Dogan, N. U.; Ozaksit, G.; Uygur, D.; Ugurlu, N. \& Ugur, M. Effect of strontium ranelate on serum leptin and bone turnover markers in women with established postmenopausal osteoporosis. J. Reprod. Med., 58(7-8):319-23, 2013.

Benic, G. I.; Thoma, D. S.; Muñoz, F.; Sanz Martin, I.; Jung, R. E. \& Hämmerle, C. H. Guided bone regeneration of peri-implant defects with particulated and block xenogenic bone substitutes. Clin. Oral Implants Res., 27(5):567-76, 2016.

Canalis, E.; Hott, M.; Deloffre, P.; Tsouderos, Y. \& Marie, P. J. The divalent strontium salt S12911 enhances bone cell replication and bone formation in vitro. Bone, 18(6):517-23, 1996.

Chen, X.; Zhou, X. C.; Liu, S.; Wu, R. F.; Aparicio, C. \& Wu, J. Y. In vivo osseointegration of dental implants with an antimicrobial peptide coating. $J$. Mater. Sci. Mater. Med., 28(5):76, 2017.

Chuka, R.; Abdullah, W.; Rieger, J.; Nayar, S.; Seikaly, H.; Osswald, M. \& Wolfaardt, J. Implant utilization and time to prosthetic rehabilitation in conventional and advanced fibular free flap reconstruction of the maxilla and mandible. Int. J. Prosthodont., 30(3):289-94, 2017.

Dhaliwal, J. S.; Albuquerque, R. F. Jr.; Murshed, M. \& Feine, J. S. Osseointegration of standard and mini dental implants: a histomorphometric comparison. Int. J. Implant Dent., 3(1):15, 2017.

Kaitsas, R.; Paolone, M. G. \& Paolone, G. Guided orthodontic regeneration: A tool to enhance conventional regenerative techniques in implant surgery. Int. Orthod., 13(4):539-54, 2015.

Kim, H. J.; Kim, Y. K.; Joo, J. Y. \& Lee, J. Y. A resonance frequency analysis of sandblasted and acid-etched implants with different diameters: a prospective clinical study during the initial healing period. J. Periodontal Implant Sci., 47(2):106-15, 2017.

Kim, Y.; Kim, T. K. \& Leem, D. H. Clinical study of a flap advancement technique without vertical incision for guided bone regeneration. Int. J. Oral Maxillofac. Implants, 30(5):1113-8, 2015.

Kolk, A.; Handschel, J.; Drescher, W.; Rothamel, D.; Kloss, F.; Blessmann, M.; Heiland, M.; Wolff, K. D. \& Smeets, R. Current trends and future perspectives of bone substitute materials - from space holders to innovative biomaterials. $J$. Craniomaxillofac. Surg., 40(8):706-18, 2012.

Le, B. \& Burstein, J. Esthetic grafting for small volume hard and soft tissue contour defects for implant site development. Implant Dent., 17(2):136-41, 2008.

Schiegnitz, E.; Kämmerer, P. W.; Sagheb, K.; Wendt, A. J.; Pabst, A.; Al-Nawas, B. $\&$ Klein, M. O. Impact of maxillary sinus augmentation on oral health-related quality of life. Int. J. Implant Dent., 3(1):10, 2017.

Zarandi, A. \& Novin, M. Marginal bone loss around platform-switched and nonplatform switched implants after two years of placement: a clinical trial. J. Dent. Res. Dent. Clin. Dent. Prospects, 11(1):26-9, 2017.

Corresponding author:

Li Bing

Stomatology Hospital

Shanxi Medical University

63 Xinjian Road, Taiyuan 030001

CHINA

Email: libing-1975@163.com

Received: 15-07-2017

Accepted: 21-09-2017 